\title{
Genetic Diversity of Human Immunodeficiency Virus Type 1 in Asymptomatic Blood Donors in Islamabad, Pakistan
}

\author{
Usman Waheed ${ }^{1,2}$ Farooq Ahmed Noor ${ }^{3}$ Noor e Saba ${ }^{4} \quad$ Akhlaaq Wazeer $^{3}$ Zahida Qasim ${ }^{3}$ \\ Muhammad Arshad $^{5}$ Saira Karimi ${ }^{6} \quad$ Ahmad Farooq $^{5}$ Javaid Usman ${ }^{7}$ Hasan Abbas Zaheer ${ }^{1,8}$
}

${ }^{1}$ Department of Pathology and Transfusion Medicine, Shaheed Zulfiqar Ali Bhutto Medical University, Islamabad, Pakistan

2Islamabad Blood Transfusion Authority, Ministry of National Health

Services, Government of Pakistan, Islamabad, Pakistan

${ }^{3}$ Department of Pathology and Transfusion Medicine, Divisional

Headquarters Teaching Hospital, Mirpur, Azad Jammu and

Kashmir, Pakistan

${ }^{4}$ Department of Health, Peshawar Regional Blood Centre,

Khyber Pakhtunkhwa, Pakistan

${ }^{5}$ Department of Biological Sciences, International Islamic

University, Islamabad, Pakistan

\author{
Address for correspondence Usman Waheed, PhD, Department \\ of Pathology and Transfusion Medicine, Shaheed Zulfiqar Ali Bhutto \\ Medical University, Islamabad 44000, Pakistan \\ (e-mail: drusman.waheed1@gmail.com). \\ ${ }^{6}$ Department of Biosciences, COMSATS University, Islamabad, \\ Pakistan \\ ${ }^{7}$ Department of Pathology, Army Medical College, National \\ University of Medical Sciences, Rawalpindi, Pakistan \\ 8 Safe Blood Transfusion Programme, Ministry of National Health \\ Services, Government of Pakistan, Islamabad, PakistanIntroduction
}

J Lab Physicians:2020;12:92-97

\begin{abstract}
Objective The serological testing of human immunodeficiency virus (HIV) is mandatory under the blood safety legislation of Pakistan; hence, data exist on the prevalence of HIV in blood donors. However, little is known about the molecular epidemiology of HIV in the blood donor population. Therefore, the current study was designed to study the genetic diversity of HIV-1 infection in a population of apparently healthy treatment-naive blood donors in Islamabad, Pakistan.

Material and Methods A total of 85,736 blood donors were tested for HIV by the chemiluminescence immunoassay. All positive donor samples were analyzed for the presence of various HIV genotypes (types and subtypes). Viral ribonucleic acid was extracted from blood samples of HIV positive donors and reverse transcribed into complementary deoxyribonucleic acid (cDNA). The cDNA of all positive donors was then analyzed for the presence of various HIV genotypes (types and subtypes) by employing subtype-specific primers in a nested polymerase chain reaction. The amplified products were run on ethidium bromide-stained $2 \%$ agarose gel and visualized using a ultraviolet transilluminator. A particular subtype was assigned to a sample if the subtype-specific reaction made a band $20 \%$ highly intense compared with the band made by the subtype-independent reaction.

Results A total of 85,736 blood donors were screened for the presence of antibodies

Keywords

- HIV

- AIDS

- blood

- donors

- genotypes

- epidemiology in $112(0.13 \%)$ positive donors, 95\% confidence interval $0.0014(0.0011-0.0018)$. These 112 samples were analyzed for molecular typing of HIV-1. The predominant HIV-1 subtype was A ( $n=101)$ (90.1\%) followed by subtype B $(n=11)(9.9 \%)$.

Conclusion These findings are key to understand the diversified HIV epidemic at the molecular level and should assist public health workers in implementing measures to lessen the further dissemination of these viruses in the country.
\end{abstract}

DoI https://doi.org/

10.1055/s-0040-1716593

ISSN 0974-2727.
(C)2020 by The Indian Association

of Laboratory Physicians
License terms

(1) (1) $\Theta \circledast$ 
The human immunodeficiency virus (HIV) is the causative agent of acquired immunodeficiency syndrome (AIDS) in humans which leads to progressive failure of the immune system ${ }^{1}$ allowing life-threatening opportunistic infections to flourish. ${ }^{2}$ The epidemiologic and phylogenetic studies suggest that HIV was introduced to humans from 1920 to $1940{ }^{3}$ HIV is a single-stranded ribonucleic acid (RNA) retrovirus surrounded by an envelope with glycoproteins (gp) 120 and gp41 responsible for viral attachment to the host. Classified as HIV-1 and HIV-2 on the genetic differences and other genetic characteristics, both types have many similarities such as mode of transmission and basic gene arrangement, among others. ${ }^{4} \mathrm{HIV}-1$ has evolved from nonhuman primate immunodeficiency virus from Central African chimpanzees (SIVcpz) whereas HIV-2 evolved from the West African sooty mangabeys (SIVsm). ${ }^{5} \mathrm{HIV}-1$ incidence is global while HIV-2 is largely limited to West Africa. ${ }^{6}$

The AIDS pandemic has had a devastating multifaceted effect on the lives of people globally. According to the World Health Organization (WHO) estimates, HIV has infected approximately 70 million people since 1981 and is responsible for the death of more than 32 million people so far. By the end of 2018, around 37.9 million population were found to be living with HIV worldwide with 1.7 million people becoming newly infected in 2018.?

Pakistan, a developing nation of 220 million inhabitants, is witnessing an increase in the number of HIV-infected individuals. The epidemic is now well established and intensifying in injection drug users and the sex workers (including male and transgender sex workers), forming the core of the epidemic. ${ }^{89}$ According to the National AIDS Control Program, 180,000 individuals are living with HIV/AIDS in the country, 39,529 are registered while 22,947 are receiving antiretroviral therapy. ${ }^{10}$ The number of infected individuals will be much higher if systematic mass screening is performed nationally.

It is imperative to strengthen knowledge and evidence about HIV/AIDS in responding effectively to the global epidemic. Countries around the globe have invested in clinical and molecular research that tries to inhibit, treat, or remedy HIV/AIDS, as well as vital research about the characteristics of HIV as a communicable agent and AIDS as the syndrome instigated by HIV. But still more research is essential to support the millions of individuals whose health remains at risk by the global HIV/AIDS pandemic. Testing for molecular epidemiology of HIV infection is of paramount importance to develop sensitive diagnostic tools, to manage individual infections, and also to keep track of transmission patterns, prevalence, and evolution of the pandemic. ${ }^{11}$

In Pakistan, molecular epidemiology investigations are currently at infancy and have yet to contribute to the formulation of a well-versed HIV prevention policy and programming. The earlier reported data on HIV-1 genotypes showed the epidemic is vastly diverse involving cocirculation of genotypes mainly "A" followed by genotypes "B," CRF_AE, CRF_ AG. ${ }^{12-14}$ Despite this molecular characterization of the diverse genetic complexity of HIV-1 among various high-risk groups in Pakistan, the genotypic prevalence of HIV-1 among the blood donor population has yet to be explored. According to WHO, an estimated 117.4 million blood donations take place each year ${ }^{15}$ and transfusion of contaminated blood and blood components carries a significant risk of transmitting bloodborne infections including HIV, and hepatitis B and C to the patients. Transmission of HIV infection due to contaminated blood and blood components transfusion has been reported repeatedly since $1982 .{ }^{16}$ In Pakistan, the incidence of HIV infection in healthy donors ranged from $0.008 \%$ in Peshawar city to $1.0 \%$ in Gwadar city. ${ }^{17}$ Assessing the pattern of HIV in blood donors is crucial to guarantee the safety of blood and also to sensitize the policymakers on the level of the disease in the apparently healthy population. Hence, this study aimed to characterize the genetic diversity of HIV-1 infection among a population of apparently healthy treatment-naive blood donors in Islamabad from 2016 to 2018.

\section{Material and Methods}

This was a cross-sectional, prospective single-center study conducted at the Department of Pathology and Transfusion Medicine, Shaheed Zulfiqar Ali Bhutto Medical University, Islamabad, Pakistan, from January 2016 to December 2018. The study protocol was endorsed by the Ethics Committee of the Shaheed Zulfiqar Ali Bhutto Medical University, Islamabad.

All the data and samples were kept confidential and anonymous. HIV analyses were performed according to the conditions of " 5 -Cs": comprising of informed consent, be confidential, involve counseling, deliver correct test results, and connections to prevention, treatment, and care services. Informed written consent was received from all study participants enrolled in this study. Clinical and epidemiological data were maintained only for therapeutic and research purposes. No monetary incentive was offered.

The blood donors were selected after careful examination in the donor management department of the blood bank following the national guidelines. ${ }^{18}$ According to general inclusion criteria, a donor aged 18 to 60 years, weight $>50 \mathrm{~kg}$, and hemoglobin level of $>12.5 \mathrm{~g} / \mathrm{dL}$ were selected. Pulse (60-100 beats per minute) and blood pressure (systolic not more than 160 and diastolic not more than $100 \mathrm{~mm}$ of $\mathrm{Hg}$ without medication) were checked as well. Any potential donor with pregnancy, lactation, recent blood donation, and vaccination were temporarily deferred. In addition, the donors answered a detailed history questionnaire about their health to determine any risk factor that can temporarily or permanently defer a donor.

\section{Serological Analyses}

A total of 85,736 blood donors were screened for HIV along with other transfusion-transmitted infections (TTIs) during the study period. HIV screening was performed by the chemiluminescence immunoassay (CLIA) using a fully automated Abbott Architect i2000SR system. The CLIA HIV is a combo immunoassay which is a two-step procedure to detect the presence of HIV-1 p24 antigen and antibodies to 
HIV-1 (groups M and O) and HIV-2. The system measures the cutoff by utilizing the mean chemiluminescent signal (relative light units) from three copies of the Calibrator 1 and records the result. The samples tested positive were retested using Abbott's CLIA system. The plasma samples were stored at $-80^{\circ} \mathrm{C}$ for further molecular analyses.

\section{Molecular Analyses}

Viral RNA was extracted from blood samples of HIV positive donors using ExiPrepDx Viral RNA extraction kit. Extraction was performed according to the manufacturer's protocol and included sample preparation, extraction process setup, pipetting samples into the specimen loading tubes, and executing the extraction by operating the ExiPrep16 Dx. The extracted viral RNA was automatically loaded into the elution tubes. After the RNA extraction, reverse transcription procedure was followed where the RNA was reverse transcribed using a commercially available kit (Thermo Fisher Scientific) into complementary deoxyribonucleic acid (cDNA) through utilizing total viral RNA, an enzyme reverse transcriptase, a primer, deoxynucleoside triphosphates, and an RNase inhibitor. The synthesized cDNA was quantified by Nanodrop-1000 spectrophotometer (Thermal Scientific, Wilmington, Massachusetts, United States). HIV cDNA of all positive donors was then analyzed for the presence of various HIV genotypes (types and subtypes) by employing subtype-specific primers in a nested polymerase chain reaction (PCR) as described below.

\section{Polymerase Chain Reaction}

\section{Standardization of PCR}

The $\beta$-globin was used as a control for DNA extraction, and PCR was performed with PC03 and PC04 primers (- Table 1).

\section{HIV-1 Subtyping}

Nested PCR was done to ensure HIV-1 infection as conditions described by Kato et al, ${ }^{19}$ to differentiate subtypes A, B, C, and CRF01AE in the env $\mathrm{C} 2 \mathrm{~V} 3 \mathrm{C} 3$ region.

Table $1 \beta$-globin amplification, PCR conditions, and primers used

\begin{tabular}{|c|c|}
\hline $\begin{array}{l}\text { The } 25 \mu \mathrm{L} \text { of PCR mixture (final) } \\
\text { included: } \\
5 \mu \mathrm{L} \text { of sample, } \\
1 \times \text { PCR buffer, } \\
1 \mathrm{mM} \mathrm{MgCl} 2,200 \mu \mathrm{M} \text { of dNTPs, } \\
0.2 \text { pmol of each primer, } \\
0.2 \mathrm{U} \text { of Taq polymerase }\end{array}$ & $\begin{array}{l}\text { Thermocycling conditions } \\
5 \text { min at } 95^{\circ} \mathrm{C} \\
39 \text { cycles: } \\
30 \text { s at } 95^{\circ} \mathrm{C} \\
30 \text { s at } 53^{\circ} \mathrm{C} \\
30 \text { s at } 72^{\circ} \mathrm{C} \\
5 \text { min at } 72^{\circ} \mathrm{C}\end{array}$ \\
\hline Primer & Sequence \\
\hline PC03 & ACACAACTGTGTTCACTAGC \\
\hline PC04 & CAACTTCATCCACGTTCACC \\
\hline
\end{tabular}

Abbreviations: dNTP, deoxynucleoside triphosphate; PCR, polymerase chain reaction. env V3 viral DNA Sequences were Amplified by Nested PCR as Follows

For both first and second round of PCR, the total $25 \mu \mathrm{L}$ reaction mixture was made.

\section{First Round of PCR}

The first round of PCR was done using $0.5 \mu \mathrm{L}$ primer sets JA9AE, JA9B, JA12A, and JA12B. The condition is presented in - Table 2.

\section{Second Round of PCR}

Note that $1.5 \mu \mathrm{L}$ of the amplified product from the first round of PCR was taken to perform the second round of PCR.

\section{Upstream Primers}

The upstream primers were mixture of three primers $(03 \mu \mathrm{L}$ each). The upstream primers are shown in - Table 3.

\section{Downstream Primers}

For subtype-independent amplification, a three-primer mixture was used $(0.3 \mu \mathrm{L})$. The downstream primers are shown in - Table 4.

Table 2 HIV-1 subtyping first round PCR conditions and primers used

\begin{tabular}{|l|l|}
\hline $1 \times$ PCR buffer, & Thermocycling conditions \\
$1 \mathrm{mM} \mathrm{MgCl}$ & \\
$200 \mathrm{mM}$ of dNTPs, & $95^{\circ} \mathrm{C}$ \\
$0.2 \mathrm{pmol}$ of each primer, & 39 cycles: \\
$0.2 \mathrm{U}$ of Taq polymerase & 30 s at $95^{\circ} \mathrm{C}$ \\
& $\begin{array}{l}30 \text { s at } 53^{\circ} \\
30 \text { s at } 72^{\circ} \mathrm{C} \\
5 \text { min at } 72\end{array}$ \\
& \\
\hline Primer & Sequence \\
\hline JA9AE & CACAGTACAATGCACACATG \\
\hline JA9B & CACAGTACAATGTACACATG \\
\hline JA12A & GCAATAGAAAAATTCTCCTC \\
\hline JA12B & ACAGTAGAAAAATTCCCCTC \\
\hline
\end{tabular}

Abbreviations: dNTP, deoxynucleoside triphosphate; HIV, human immunodeficiency virus; PCR, polymerase chain reaction.

Table 3 The upstream primers used for HIV-1 subtyping

\begin{tabular}{|l|l|}
\hline Primer & Sequence \\
\hline JA10UB & CTGTTAAATGGCAGTCTAGC \\
\hline JA10UC & CTGTTAAATGGTAGTCTAGC \\
\hline JA10UG & CTGTTAAATGGCAGTTTAGC \\
\hline
\end{tabular}

Abbreviation: HIV, human immunodeficiency virus.

Table 4 The downstream primers used for HIV-1 subtyping

\begin{tabular}{|l|l|}
\hline Primer & Sequence \\
\hline JA11LAE & AATTTCTAGATCCCCTCCTG \\
\hline JA11LB & AATTTCTGGGTCCCCTCCTG \\
\hline JA11LC & AATTTCTAGGTCCCCTCCTG \\
\hline
\end{tabular}

Abbreviation: HIV, human immunodeficiency virus. 
Table 5 Thermocycling conditions for second round of PCR

$$
\begin{aligned}
& 5 \text { min at } 95^{\circ} \mathrm{C} \text {; } \\
& 39 \text { cycles: } \\
& 20 \text { s at } 95^{\circ} \mathrm{C} \\
& 30 \text { s at } 58^{\circ} \mathrm{C} \\
& 50 \text { s at } 72^{\circ} \mathrm{C} \\
& 5 \text { min at } 72^{\circ} \mathrm{C}
\end{aligned}
$$

Abbreviation: PCR, polymerase chain reaction.

For subtype A: $1 \mu \mathrm{M}$ of JA11QA was used
(CCCCTCCTGAGGAGTTAGCA).
For subtype B: $1 \mu \mathrm{M}$ of JA11VB was used
(CACAATTAAAACTGTGCATTACAA).
For subtype C: $1 \mu \mathrm{M}$ of JA11XC was used
(TTGTTTATTAGGGAAGTGTT) ${ }^{2}$.
$\quad$ For subtype CRF01-AE: $1 \mu \mathrm{M}$ of JA11YE was used
(AAATTCCCTCTACAATTAAAATGA).

The thermocycling conditions for second round of PCR are been presented in $\boldsymbol{- T a b l e ~} \mathbf{5}$.

After the completion of PCR, $4.5 \mu \mathrm{L}$ of gag reference amplicon was combined with an unknown sample's gag amplicon $(4.5 \mu \mathrm{L})$. In addition, $1 \mu \mathrm{L}$ of $10 \times$ heteroduplex annealing buffer was added (which included $1 \mathrm{M} \mathrm{NaCl}$, $20 \mathrm{mM}$ ethylenediaminetetraacetic acid, $100 \mathrm{mM}$ Tris $\mathrm{HCl}$, $\mathrm{pH}$ 7.8). This reaction mixture was placed for heating for 2 minutes at $95^{\circ} \mathrm{C}$. This was followed by immediate cooling by placing on ice.

The amplified products were run on ethidium bromide-stained $2 \%$ agarose gel and visualized using a ultraviolet transilluminator. Using the protocol of Kato et $\mathrm{al}^{19}$ a particular subtype was assigned to a sample, if the subtype-specific reaction made a band $20 \%$ highly intense compared with the band made by the subtype-independent reaction.

For the blood donor population, the frequencies, percentages, and confidence interval $(\mathrm{CI})$ were calculated using Statistical Package for Social Sciences version 20 (IBM SPSS Statistics for Windows, Version 20.0, IBM Corp.).

\section{Results}

A total of 85,736 blood donors were screened for the presence of antibodies to HIV during the period 2016 through 2018. Of these donors, 85,199 (99.38\%) were males and 537 (0.62\%) donors were females. Out of them, 114 were found initially reactive for HIV. The repeat testing resulted in 112 (0.13\%) positive donors, $95 \% \mathrm{CI} 0.0014$ (0.0011-0.0018). All positive donors were males.

The number of samples analyzed for HIV- 1 genotypic analysis was 112 . The technique applied for analysis is the subtype-specific PCR. From the analysis of 112 HIV positive individuals, the predominant HIV- 1 subtype was A $(n=101)$ (90.1\%) followed by subtype B ( $n=11)(9.9 \%)$.

\section{Discussion}

HIV epidemic is still ongoing and evolving. The dynamics of the HIV epidemic are diverse in Pakistan and are growing.
This is the time to implement effective prevention and care programs to stop the spread of HIV/AIDS. The window of opportunity is the incidence rate of HIV in the general population $(<1 \%)$ which clearly offers a prospect to act decisively.

Unfortunately, the cases reported so far, only represents the "tip of the iceberg." The behaviors encouraging the spread of HIV infection to young people include increased interest in sex and drugs, negative peer pressure, and economic frustration in Pakistan. ${ }^{20}$ These vulnerabilities and patterns of risky behaviors signal the need to take action now before it is too late. The HIV epidemic is growing at an alarming rate, ${ }^{21}$ but unfortunately it is overlooked as the prevalence is mainly confined to high-risk groups who are traditionally marginalized.

Poor awareness about HIV/AIDS with lack of information, persistent scarcity of financial resources, weak regulatory oversight, and common misunderstanding that HIV only infects "individuals with bad characters" are some aspects affecting the occurrence of HIV/AIDS.

The spread of HIV infection via blood transfusions is one of the major concerns and often reports of such cases appear in the print and electronic media. According to blood safety legislation of Pakistan, screening for five markers (called TTIs) is mandatory on every blood unit collected.

The available data from blood donors show a rise in the number of HIV cases detected. The monitoring of HIV patterns in blood donors is critical to ensure the safety of blood and blood components and in addition to sensitizing the decision-makers on the magnitude of the HIV epidemic in blood donors which represent the general healthy population. In developed countries, donor behavioral screening, use of highly sensitive screening tests, and more rational use of blood and blood components have brought about a dramatic decline in the spread of HIV through blood transfusions.

The incidence of HIV reported in the present study (0.13\%) was matched with the mean HIV incidence from 1988 to 2016 which was $0.13 \%{ }^{17}$ We also compared the findings of our study with those reported by other countries. Our incidence rate of $0.13 \%$ was relatively lower than those reported by Northeast Ethiopia 5.1\%, ${ }^{22}$ Nepal $0.21 \%,{ }^{23}$ China $0.31 \%,{ }^{24}$ South Sudan 7.9\% ${ }^{25}$ Nigeria 2.8\%, ${ }^{26}$ Northwest Ethiopia 3.8\%, ${ }^{27}$ and Burkina Faso $2.21 \% 28$ but higher than those reported from India $0.1 \%,{ }^{29}$ Iran $0.001 \%,{ }^{30}$ Italy $0.00019 \%,{ }^{31}$ and Australia $0.0003 \%{ }^{32}$ There is considerable diversity in the incidence of HIV in different countries and indicate variations in the awareness programs, blood screening techniques, and other preventive measures in individual countries.

The blood safety can be enhanced through a comprehensive donor recruitment scheme with standardized behavioral and serological screening. According to previous research studies, the incidence of HIV/AIDS can be reduced to 2 in $1,000,000^{23}$ or even lesse ${ }^{24}$ through behavioral evaluation of blood donor and quality assured serological TTI screening of blood bags.

Molecular epidemiology testing for HIV is a key to track patterns of transmission and the evolution of the HIV epidemic in the general public. HIV-1 has a high genetic variability and comprised of four groups (M, N, O, and P). For the HIV 
pandemic, $M$ is the major group responsible, being further subclassified into numerous subclasses (A to K, excluding E) and several mosaic strains termed as circulating recombinant forms. ${ }^{33,34}$ Recently, researchers from the United States have also reported a group $\mathrm{M}$ subtype $\mathrm{L}$ in samples from the Democratic Republic of Congo. ${ }^{35}$

The prevalence of HIV-1 subtypes in a population follows the evolution of the epidemic. Hemelaar et a ${ }^{36}$ investigated the country-specific HIV-1 molecular epidemiology data of 65,913 specimens from 109 countries. The analyses of the worldwide pattern of HIV-1 subtypes and circulating recombinant forms specified a largely steady distribution with a noteworthy upsurge in the percentage of circulating recombinant forms, a decline in the unique recombinant forms, and a general rise in recombinants.

Our findings confirmed that " $\mathrm{A}$ " subtype is predominant HIV subtype present in our country followed by subtype "B." This outcome is consistent with earlier available reports showing the subtype $A$ as the most common subtype in Pakistan. ${ }^{12-14}$ In the study by Khan et al, ${ }^{12}$ the subtype A was $100 \%$ while it was $69.73 \%$ as reported by Khanani et al. ${ }^{13}$ The study by Chen et al, ${ }^{14}$ reported the prevalence of HIV subtype A as $47 \%$ with an increasing number of recombinant forms. According to the Los Alamos HIV databases, the national prevalence shows a high peak for subtype $\mathrm{A}$ (73.3\%). This is in contrast to the global prevalence trends where the prevalent subtype is $B(55.8 \%)^{37}$

Although this trend may shift during the course of the next few years and more subtypes may become prevalent in the country, HIV is persistently advancing ever since the pioneer case of HIV in Pakistan diagnosed in 1987,,38 and our data suggested that the B subtype was not as common in earlier reports as in our findings. This is largely because of the migrant workers who are infected and introduce new subtypes of HIV. These include laborers and commercial sex workers of bordering countries such as Afghanistan, Iran, or the Gulf States..$^{39}$ A significant number of Pakistani nationals are working in the Gulf States including the Kingdom of Saudi Arabia, Kuwait, and the United Arab Emirates. These HIVinfected persons then infect their spouses and kids and ultimately placing the general public at danger. Because of weak regulatory oversight by the government, this practice will lead us to a rapid rise in the incidence of HIV infection and will also alter the pattern of different subtypes in Pakistan.

In conclusion, the results establish HIV-1 molecular complexity among blood donors with subtypes $A$ and $B$. The findings of this study may be used for further genetic analysis and development of highly advanced assays for blood screening to ensure blood safety. Continuous efforts must be directed toward improving effective treatment and prevention strategies.

\section{Conflict of Interest}

The authors declare no potential conflict of interest.

\section{Acknowledgments}

We would like to thank Inam Ullah Marwat (IIU), Bilal Ahmed Khan Tareen (PIMS), Muhammad Umair (QAU),
Safdar Abbas (QAU), Shahan Irshad (SMS), Muhammad Nisar Khan (PIMS), Mahmood Awan (SMS), and Khawaja Junaid Shokat (SMS) for assistance and support.

\section{References}

1 Parikh UM, McCormick K, van Zyl G, Mellors JW. Future technologies for monitoring HIV drug resistance and cure. Curr Opin HIV AIDS 2017;12(2):182-189

2 Albarillo F, O'Keefe P. Opportunistic neurologic infections in patients with acquired immunodeficiency syndrome (AIDS) Curr Neurol Neurosci Rep 2016;16(1):10

3 Faria NR, Rambaut A, Suchard MA, et al. HIV epidemiology. The early spread and epidemic ignition of HIV-1 in human populations. Science 2014;346(6205):56-61

4 German Advisory Committee Blood (Arbeitskreis Blut), Subgroup 'Assessment of Pathogens Transmissible by Blood'. Human immunodeficiency virus (HIV) Transfus Med Hemother 2016;43(3):203-222

5 Gao F, Bailes E, Robertson DL, et al. Origin of HIV-1 in the chimpanzee Pan troglodytes troglodytes. Nature 1999;397(6718) :436-441

6 Nyamweya S, Hegedus A, Jaye A, Rowland-Jones S, Flanagan KL, Macallan DC. Comparing HIV-1 and HIV-2 infection: Lessons for viral immunopathogenesis. Rev Med Virol 2013;23(4):221-240

7 World Health Organization. Fact Sheet HIV/AIDS 2019. Available at: https://www.who.int/news-room/fact-sheets/ detail/hiv-aids. Accessed September 27, 2019

8 Bokhari A, Nizamani NM, Jackson DJ, et al. HIV risk in Karachi and Lahore, Pakistan: an emerging epidemic in injecting and commercial sex networks. Int J STD AIDS 2007;18(7):486-492

9 Emmanuel F, Salim M, Akhtar N, Arshad S, Reza TE. Secondgeneration surveillance for HIV/AIDS in Pakistan: results from the 4th round of Integrated Behavior and Biological Survey 2011-2012. Sex Transm Infect 2013;89(3, Suppl 3) :iii23-iii28

10 National AIDS Control Programme, Government of Pakistan. Available at: https://www.nacp.gov.pk/. Accessed December 27, 2019

11 Abu-Raddad LJ, Hilmi N, Mumtaz G, et al. Epidemiology of HIV infection in the Middle East and North Africa. AIDS 2010;24(2, Suppl 2) :S5-S23

12 Khan S, Rai MA, Khanani MR, Khan MN, Ali SH. HIV-1 subtype A infection in a community of intravenous drug users in Pakistan. BMC Infect Dis 2006;6:164

13 Khanani MR, Somani M, Rehmani SS, Veras NMC, Salemi M, Ali SH. The spread of HIV in Pakistan: bridging of the epidemic between populations. PLoS One 2011;6(7):e22449

14 Chen Y, Hora B, DeMarco T, et al. Fast dissemination of new HIV-1 CRF02/A1 recombinants in Pakistan. PLoS One 2016;11(12):e0167839

15 World Health Organization. Fact Sheet on blood safety and availability. Available at: https://www.who.int/news-room/factsheets/detail/blood-safety-and-availability. Accessed September 27, 2019

16 Ammann AJ, Cowan MJ, Wara DW, et al. Acquired immunodeficiency in an infant: possible transmission by means of blood products. Lancet 1983;1(8331):956-958

17 Waheed U, Arshad M, Usman J, Farooq A, Wazeer A, Zaheer HA. Surveillance of human immunodeficiency virus in blood donors of Islamabad, Pakistan: a meta-analysis. Pak Armed Forces Med J 2017;67(5):860-867

18 Zaheer HA, Ahmed S, Waheed U, Wazeer A. National Guidelines for Quality Control in Transfusion Medicine. 2nd ed. Islamabad: SBTP, Ministry of National Health Services, Pakistan; 2020:49-56. Available at: https:// www.sbtp.gov.pk/wp-content/uploads/2020/03/ 
National-Guidelines-Quality-Control-in-TransfusionMedicine-2020.pdf. Accessed January 27, 2020

19 Kato S, Saito R, Hiraishi Y, et al. Differential prevalence of HIV type 1 subtype B and CRF01_AE among different sexual transmission groups in Tokyo, Japan, as revealed by subtype-specific PCR. AIDS Res Hum Retroviruses 2003;19(11):1057-1063

20 Abrar N, Ghouri AM. AIDS/HIV knowledge, attitude and beliefs of adolescents of Pakistan. Eur J Soil Sci 2016;16(2):275-285

21 Waheed U, Zaheer HA. Possible transmission of human immunodeficiency virus through blood transfusion in Pakistan. Glob J Transfus Med 2019;4(1):117-118

22 Sharew B, Mulu A, Teka B, Tesfaye T. HIV-Sero-prevalence trend among blood donors in North East Ethiopia. Afr Health Sci 2017;17(3):712-718

23 Shrestha AC, Ghimire P, Tiwari BR, Rajkarnikar M. Transfusiontransmissible infections among blood donors in Kathmandu, Nepal. J Infect Dev Ctries 2009;3(10):794-797

24 Song Y, Bian Y, Petzold M, Ung COL. Prevalence and trend of major transfusion-transmissible infections among blood donors in Western China, 2005 through 2010. PLoS One 2014;9(4):e94528

25 Sube KL, Serianoa OF, Gorea RP, et al. The prevalence of HIV among blood donors at Juba Teaching Hospital Blood Bank, South Sudan. South Sudan Med J 2014;7(4):76-80

26 Hassan A, Muktar HM, Mamman AI, Ahmed AJ, Isa AH, Babadoko AA. The incidence of HIV among blood donors in Kaduna, Nigeria. Afr Health Sci 2007;7(4):253

27 Tessema B, Yismaw G, Kassu A, et al. Seroprevalence of HIV, HBV, HCV and syphilis infections among blood donors at Gondar University Teaching Hospital, Northwest Ethiopia: declining trends over a period of five years. BMC Infect Dis 2010;10:111

28 Nagalo MB, Sanou M, Bisseye C, et al. Seroprevalence of human immunodeficiency virus, hepatitis B and C viruses and syphilis among blood donors in Koudougou (Burkina Faso) in 2009. Blood Transfus 2011;9(4):419-424
29 Ahmed Z, Umaru N, Shreesha K. Seroprevalence of transfusion transmitted infections among blood donors in Mangalore. Journal of Medical Innovates 2012;1(2):24-27

30 Mohsenizadeh M, Mollaei HR, Ghaziizadeh M. Seroepidemiological study of hepatitis B, C and HIV among blood donors in Kerman. Asian Pac J Cancer Prev 2017;18(12): 3267-3272

31 Gonzalez M, Règine V, Piccinini V, Vulcano F, Giampaolo A, Hassan HJ. Residual risk of transfusion-transmitted human immunodeficiency virus, hepatitis C virus, and hepatitis B virus infections in Italy. Transfusion 2005;45(10):1670-1675

32 Polizzotto MN, Wood EM, Ingham H, Keller AJ; Australian Red Cross Blood Service Donor and Product Safety Team. Reducing the risk of transfusion-transmissible viral infection through blood donor selection: the Australian experience 2000 through 2006. Transfusion 2008;48(1):55-63

33 Woodman Z, Williamson C. HIV molecular epidemiology: transmission and adaptation to human populations. Curr Opin HIV AIDS 2009;4(4):247-252

34 Lau KA, Wong JJ. Current trends of HIV recombination worldwide. Infect Dis Rep 2013;5(Suppl 1) :e4

35 Yamaguchi J, Vallari A, McArthur C, et al. Brief report: complete genome sequence of CG-0018a-01 establishes HIV-1 subtype L. J Acquir Immune Defic Syndr 2020;83(3):319-322

36 Hemelaar J, Gouws E, Ghys PD, Osmanov S; WHO-UNAIDS Network for HIV Isolation and Characterisation. Global trends in molecular epidemiology of HIV-1 during 2000-2007. AIDS 2011;25(5):679-689

37 Los Alamos National Laboratory. HIV databases. Available at: https://www.hiv.lanl.gov/content/index. Accessed November 27, 2019

38 Khanani RM, Hafeez A, Rab SM, Rasheed S. Human immunodeficiency virus-associated disorders in Pakistan. AIDS Res Hum Retroviruses 1988;4(2):149-154

39 Shah SA, Khan OA, Kristensen S, Vermund SH. HIV-infected workers deported from the Gulf States: impact on Southern Pakistan. J Pak Med Assoc 2006;56(1, Suppl 1) :S22-S24 